\title{
EVALUASI IMPLEMENTASI KEBIJAKAN BADAN LAYANAN UMUM DAERAH DI RSUD Dr SOEGIRI LAMONGAN
}

\author{
Alifatul Mahmudah Nuryanawati \\ Universitas Islam Lamongan
}

\begin{abstract}
ABSTRAK
Salah satu hal yang penting dalam perubahan adalah ciri sekuensial atau pentahapan waktu dalam perubahan. Seperti perubahan RSUD dalam Pola Pengelolaan Keuangan dari SKPD menjadi BLUD. Pelaksanaan penerapan BLUD RSUD Dr Soegiri sesuai dengan acuan Permedagri No 61 Tahun 2007 dan Permendagri No 79 Tahun 2018. Paradigma baru sebagai sebuah BLUD juga harus seimbang yaitu tetap berorientasi pada peningkatan pelayanan pada masyarakat. Sebagaimana diamanatkan dalam Permendagri No. 61 Tahun 2007 dan Permendagri No. 79 Tahun 2018 tentang Pedoman Teknis Pengelolaan Keuangan Badan Layanan Umum Daerah, sebagai sebuah $R S$ yang menerapkan PPK - BLUD maka perlu adanya evaluasi kinerja. Metode Penelitian yang dilakukan metode analisis deskriptif secara kualitatif dengan rancangan studi kasus. Pengambilan sampel pada penelitian ini dilakukan secara purposive sampling. Metode pengumpulan data diperoleh melalui wawancara mendalam, observasi, dan pemanfaatan dokumen. Peneliti bertindak sebagai pelaksana, pengumpul data, analisis, penafsiran data, dan hasil penelitian. Hasil Penelitian adalah pelaksanaan penerapan BLUD berdasarkan hasil kajian evaluasi di RSUD Dr Soegiri menunjukkan bahwa kinerja keuangan belum optimal sedangkan untuk penyusunan laporan keuang telah sesuai standar akuntansi keuangan ( SAK ) dan telah diaudit oleh KAP. Aspek pelayanan juga belum optimal. Penerapan yang belum sesuai dengan kriteria adalah standar pelayanan minimal ( SPM ) belum bisa dilaksanakan secara optimal sesuai dengan indicator dan kriteria SPM. Dewan Pengawas belum melaksanakan kewajiban sesuai dengan ketentuan. Pola Tata Kelola, RBA dan Laporan Keuangan telah sesuai dengan stnadra, sedangkan SPM, Dewan Pengawas belum dijalankan secara optimal sesuai standar dan kriteria yang ditetapkan.
\end{abstract}

Kata Kunci : PPK - BLUD, Penerapan BLUD, Rumah Sakit

\section{PENDAHULUAN}

Saat ini pada instansi pelayanan publik baik milik swasta maupun pemerintah sangat dituntut pelayanan yang prima. Pelayanan pelanggan yang bermutu merupakan kunci sukses dan dasar untuk membangun keberhasilan dan kepercayaan pelanggan. Namun, pelayanan publik oleh aparatur pemerintah saat ini masih banyak dijumpai kelemahan sehingga belum dapat memenuhi kualitas yang diharapkan masyarakat.

Rumah Sakit Umum Daerah (RSUD) sebagai penyelenggara pelayanan publik dibidang kesehatan saat ini belum memenuhi harapan masyarakat. Seringkali administrasi yang berbelit-belit akibat kakunya birokrasi salah satu hal yang sering 
dikeluhkan oleh masyarakat. Hal yang mendasari pelayanan publik masih belum memenuhi keinginan masyarakat penggunanya adalah pola pengelolaan anggaran pada organisasi publik yang cenderung kaku. Berbagai upaya peningkatan kualitas pelayanan publik sudah dilakukan ditandai dengan dikeluarkan Permendagri No 61 Tahun 2007 tentang Pedoman Teknis Pengelolaan Badan Layanan Umum Daerah (BLUD).

Latar belakang perlunya menjadi Badan Layanan Umum Daerah adalah RSUD Dr Soegiri sebelum menjadi BLUD tak sedikit keluhan selama ini diarahkan pada kualitas pelayanan rumah sakit yang dinilai masih rendah. Terutama rumah sakit pemerintah khususnya RSUD Dr Soegiri dengan masalah yang sangat klasik, yaitu masalah keterbatasan dana yang dimiliki sehingga tidak bisa mengembangkan mutu layanannya, masalah biaya pelayanan kesehatan yang semakin tinggi. Tarif yang diberlakukan harus kompetitif, dan tuntutan mutu pelayanan yang baik dalam rangka penyelamatan jiwa dan kesembuhan penyakit serta dapat memuaskan pelanggan. Sehingga pada tahun 2009 RSUD Dr. Soegiri berupaya semaksimal mungkin agar dapat ditetapkan sebagai Badan Layanan Umum Daerah ( BLUD ). Dan berdasarkan SK Bupati Nomor 188/224/Kep/413.013/2009 tanggal 9 September 2009 maka per 01 Januari 2010 RSUD Dr. Soegiri melaksanakan Pola Pengelolaan Keuangan BLUD (PPK-BLUD).

\section{METODOLOGI PENELITIAN}

Jenis penelitian yang dilakukan metode analisis deskriptif secara kualitatif dengan rancangan studi kasus. Pengambilan sampel pada penelitian ini dilakukan secara purposive sampling. Metode pengumpulan data diperoleh melalui wawancara mendalam, observasi, dan pemanfaatan dokumen. Peneliti bertindak sebagai pelaksana, pengumpul data, analisis, penafsiran data, dan hasil penelitian.

Subjek penelitian ini adalah RSUD Dr Soegiri Lamongan di fokuskan Direktur RSUD Dr Soegiri, Wadir Pelayanan dan Penunjang, Wadir Umum dan Keuangan, Kabid Pelayanan, Kabid Penunjang, Kabag Program, Kabag Umum, Kabag Keuangan sebagai PPK BLUD. 
3. HASIL PENELITIAN DAN keuangan berdasarkan Standar

\section{PEMBAHASAN}

3.1 Dokumen Perencanaan dan Penganggaran

RSUD Dr. Soegiri telah menyusun perencanaan jangka menengah berupa Rencana Strategi Bisnis (RSB) untuk periode 2014 2018.

Dokumen Penganggaran untuk tahun 2017 dituangkan dalam Rencana Bisnis Anggaran (RBA) tahun 2017.

\subsection{Pelaporan Kinerja}

RSUD Dr. Soegiri telah menyusun dan menyampaikan laporan kinerja berupa Laporan Kinerja Instansi Pemerintah (LkjIP) RSUD Dr. Soegiri Lamongan Tahun 2017.

\section{A. Hasil Evaluasi}

\section{Evaluasi Kinerja Rumah Sakit}

Capaian Kinerja BLUD RSUD Dr. Soegiri Lamongan tahun 2017 adalah sebesar 77,94 dengan predikat "Baik" dalam kategori "A" dengan rincian sebagai berikut:

\section{a. Aspek Keuangan}

\section{1) Laporan Keuangan}

RSUD Dr. Soegiri Lamongan telah menyusun laporan keuangan tahun 2017 berdasarkan Standar Akuntansi Pemerintah (SAP) maupun laporan
Akuntansi Keuangan (SAK). Laporan keuangan berdasarkan SAK telah diaudit oleh auditor independen KAP Made Sudarma-Thomas-Dewi, dengan opini wajar tanpa pengecualian sesuai laporan nomor AU085/MTD/SBY/III/2018 tanggal 26 Maret 2018.

\section{2) Kinerja Aspek Keuangan}

Capaian kinerja keuangan tahun 2017 belum optimal dengan skor 18,03 atau $60,10 \%$ dari bobot 30,00 dengan rincian sebagai berikut :

\begin{tabular}{|c|c|c|c|c|}
\hline No & $\begin{array}{c}\text { Sub Aspek / } \\
\text { Indikator }\end{array}$ & Skor & Bobot & $\begin{array}{c}\% \\
\text { Capaian }\end{array}$ \\
\hline \multirow[t]{6}{*}{$\mathbf{A}$} & $\begin{array}{l}\text { Rasio } \\
\text { Keuangan }\end{array}$ & 10,85 & 19,00 & 57,11 \\
\hline & $\begin{array}{l}\text { Rasio Kas } \\
\text { (Cash Ratio) }\end{array}$ & 0,25 & 2,00 & 12,50 \\
\hline & $\begin{array}{l}\text { Rasio } \\
\text { Lancar } \\
\text { (Current } \\
\text { Ratio) }\end{array}$ & 0,50 & 2,50 & 20,00 \\
\hline & $\begin{array}{l}\text { Periode } \\
\text { Penagihan } \\
\text { Piutang } \\
\text { (Collection } \\
\text { Period) }\end{array}$ & 0,50 & 2,00 & 25,00 \\
\hline & $\begin{array}{l}\text { Perputaran } \\
\text { Aset Tetap } \\
\text { (Fixed Asset } \\
\text { Turnover) }\end{array}$ & 2,00 & 2,00 & 100,00 \\
\hline & $\begin{array}{l}\text { Imbalan atas } \\
\text { Aset Tetap } \\
\text { (Return on } \\
\text { Fixed Asset) }\end{array}$ & 2,00 & 2,00 & 100,00 \\
\hline
\end{tabular}




\begin{tabular}{|c|c|c|c|c|}
\hline No & $\begin{array}{c}\text { Sub Aspek / } \\
\text { Indikator }\end{array}$ & Skor & Bobot & $\begin{array}{c}\% \\
\text { Capaian }\end{array}$ \\
\hline & $\begin{array}{l}\text { Imbalan } \\
\text { Ekuitas } \\
\text { (Return on } \\
\text { Equity) }\end{array}$ & 1,60 & 2,00 & 80,00 \\
\hline & $\begin{array}{l}\text { Perputaran } \\
\text { Persediaan } \\
\text { (Inventory } \\
\text { Turnover) }\end{array}$ & 0,50 & 2,00 & 25,00 \\
\hline & $\begin{array}{l}\text { Rasio } \\
\text { Pendapatan } \\
\text { Operasional } \\
\text { terhadap } \\
\text { Biaya } \\
\text { Operasional }\end{array}$ & 2,50 & 2,50 & 100,00 \\
\hline & $\begin{array}{l}\text { Rasio } \\
\text { Subsidi } \\
\text { Biaya } \\
\text { Pasien }\end{array}$ & 1,00 & 2,00 & 50,00 \\
\hline \multirow[t]{7}{*}{ b } & $\begin{array}{l}\text { Kepatuhan } \\
\text { Pengelolaan } \\
\text { Keuangan }\end{array}$ & 7,68 & 11,00 & 69,81 \\
\hline & $\begin{array}{l}\text { Rencana } \\
\text { Bisnis dan } \\
\text { Anggaran } \\
\text { (RBA) } \\
\text { Definitif }\end{array}$ & 0,00 & 2,00 & 0,00 \\
\hline & $\begin{array}{l}\text { Laporan } \\
\text { Keuangan }\end{array}$ & 1,97 & 2,00 & 98,75 \\
\hline & $\begin{array}{l}\text { Pengesahan } \\
\text { Pendapatan } \\
\text { dan Belanja } \\
\text { BLU }\end{array}$ & 0,80 & 2,00 & 90,00 \\
\hline & $\begin{array}{l}\text { Tarif } \\
\text { Layanan }\end{array}$ & 1,00 & 1,00 & 100,00 \\
\hline & $\begin{array}{l}\text { Sistem } \\
\text { Akuntansi }\end{array}$ & 1,00 & 1,00 & 100,00 \\
\hline & $\begin{array}{l}\text { Persetujuan } \\
\text { Rekening }\end{array}$ & 0,50 & 0,50 & 100,00 \\
\hline
\end{tabular}

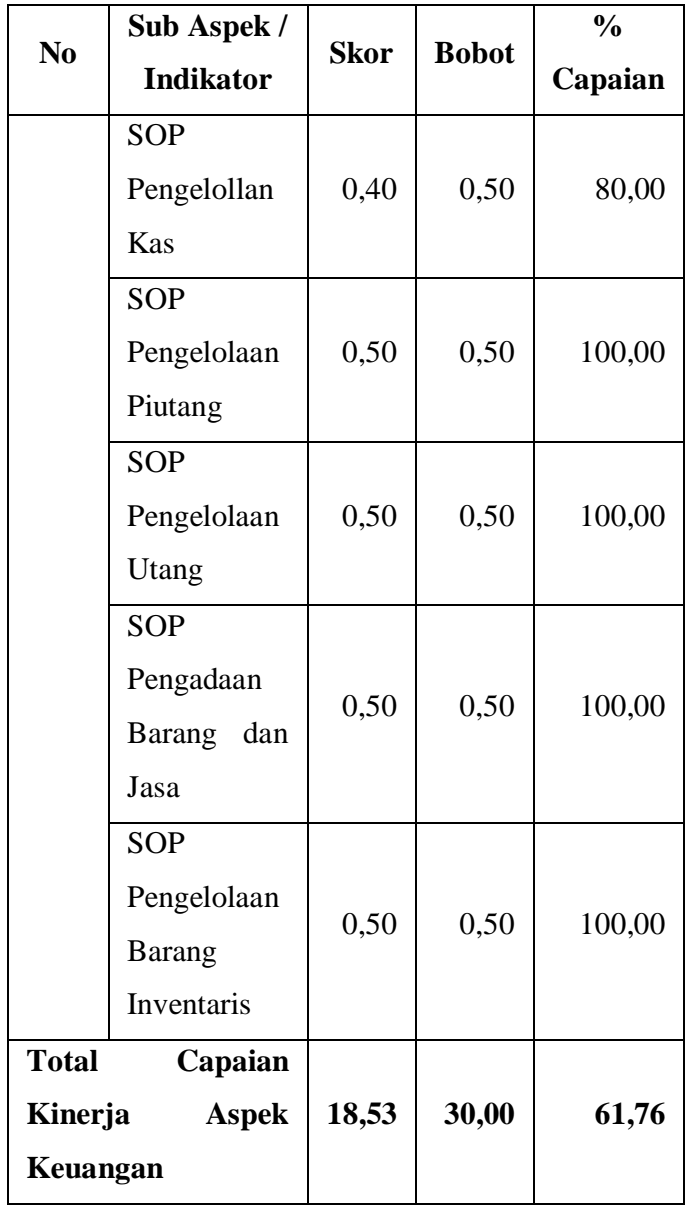

Terhadap kondisi-kondisi diatas kepada Direktur RSUD Dr. Soegiri Lamongan kami sarankan agar melakukan langkahlangkah strategis untuk meningkatkan kinerja aspek keuangan melalui :

(1) Berkoordinasi dengan BPJS Kesehatan agar pencairan piutang rumah sakit ke BPJS bisa dipercepat.

(2) Mengefisienkan penggunaan obatobatan, bahan medis habis pakai dan biaya lainnya.

(3) Meningkatkan perhatian RSUD terhadap pasien miskin.

(4) Membuat RBA definitif. 
(5) Melengkapi Laporan Keuangan

(SAP) Semester I dengan Catatan atas Laporan Keuangan (CaLK).

\section{b. Aspek Pelayanan}

Capaian kinerja pelayanan tahun 2017 belum optimal dengan skor 58,91 atau 84,16\% dari bobot 70,00 dengan rincian sebagai berikut :

\begin{tabular}{|c|c|c|c|c|}
\hline No & Sub Aspek/Indikator & Skor & Bobot & $\begin{array}{c}\% \\
\text { Capaian }\end{array}$ \\
\hline \multirow[t]{4}{*}{ a. } & Kualitas Layanan & $\mathbf{2 7 , 5 0}$ & 35,00 & $\mathbf{7 8 , 5 7}$ \\
\hline & Pertumbuhan Produktivitas & 14,00 & 18,00 & 77,78 \\
\hline & Efektivitas Pelayanan & 11,50 & 14,00 & 82,14 \\
\hline & Pertumbuhan Pembelajaran & 2,00 & 3,00 & 66,67 \\
\hline \multirow[t]{6}{*}{ b. } & Mutu dan Manfaat Kepada Masyarakat & 31,91 & 35,00 & 91,17 \\
\hline & Mutu Pelayanan & 13,00 & 14,00 & 82,14 \\
\hline & Mutu Klinik & 11,00 & 12,00 & 91,67 \\
\hline & Kepedulian Kepada Masyarakat & 3,50 & 4,00 & 87,50 \\
\hline & Kepuasan Pelanggan & 1,91 & 2,00 & 95,59 \\
\hline & Kepeduliaan Terhadap Lingkungan & 2,50 & 3,00 & 83,33 \\
\hline \multicolumn{2}{|c|}{ Total Capaian Kinerja Aspek Pelayanan } & 59,41 & 70,00 & 84,87 \\
\hline
\end{tabular}

\section{1) Sub Aspek Kualitas Layanan}

\section{a) Pertumbuhan Produktivitas}

Capaian indikator ini secara keseluruhan belum optimal dengan skor 14,00 dari bobot 18,00 .

Indikator yang belum maksimal adalah :

(1) Pertumbuhan Rata-rata Kunjungan Rawat Darurat

(2) Pertumbuhan Hari Perawatan Rawat Inap

(3) Pertumbuhan Operasi

(4) Pertumbuhan Rehab Medik
Kurang maksimalnya capaian indikator tersebut disebabkan :

(1) Adanya kegiatan renovasi gedung RSUD Dr. Soegiri Lamongan pada tahun 2017, diantaranya gedung pelayanan gawat darurat dan rawat inap, yang berdampak pada jumlah kunjungan instalasi gawat darurat dan rawat inap.

(2) Adanya dokter spesialis bedah yang melanjutkan pendidikan sehingga SDM yang berdampak kepada 
terbatasnya jumlah dokter spesialis bedah.

(3) Adanya perubahan ketentuan terkait BPJS, yaitu FKTP atau rumah sakit Type dibawah rumah sakit tujuan rujukan tidak bisa langsung merujuk pasien ke rehabilitasi medik, tetapi harus mellaui poli klinik dan tidak semua dokter di poli klinik mengarahkan pasien ke rehabilitasi medik.

\section{b) Efektivitas Pelayanan}

Capaian indikator ini secara keseluruhan belum optimal dengan skor 11,50 dari bobot 14,00 .

Indikator yang belum maksimal adalah :

(1) Kelengkapan rekam medik 24 jam selesai pelayanan

(2) Pengembalian rekam medik

(3) Angka pembatalan operasi

Kurang maksimalnya capaian indikator tersebut disebabkan :

(1) Kurang patuhnya setiap PPA (Petugas Pemberi Asuhan) dalam menuliskan catatan ke dalam berkas rekam medik segera setelah selesai memberikan pelayanan kepada pasien, sehingga berdampak pada kurang lengkapnya pengisian rekam medik 24 jam selesai pelayanan.
(2) Petugas rekam medik menunggu kelengkapan pengisian rekam medik untuk melaksanakan pengembalian.

(3) Terdapat kondisi dimana pasien tidak memungkinkan utuk dilakukan tindakan operasi, antara lain karena tensi darah tidak stabil, anemia, gula darah, kerusakan alat, kurangnya jumlah instrumen dan keterbatasan jumlah kamar operasi sehingga berdampak pada angka pembatalan operasi tinggi.

\section{c) Pertumbuhan Pembelajaran}

Capaian indikator ini secara keseluruhan belum optimal dengan skor 2,00 dari bobot 3,00. Indikator yang belum maksimal adalah rata-rata jam pelatih/karyawan.

Kurang maksimalnya capaian indikator tersebut disebabkan capaian dihitung atas pelatihan karyawan yang diniayai oleh rumah sakit dan kebutuhan pemenuhan capaian jam pelatihan untuk karyawan tidak sebanding dengan anggaran yang tersedia, sehingga tidak semua pelatihan karyawan bisa dibiayai oleh rumah sakit. 
2) Sub Aspek Mutu dan Manfaat kepad Masyarakat

\section{a) Mutu Pelayanan}

Capaian indikator ini secara keseluruhan belum optimal dengan skor 13,00 dari bobot 14,00 . Indikator yang belum maksimal adalah :

(1) Length of stay

(2) Kecepatan pelayanan resep obat jadi Kurang maksimalnya capaian indikator tersebut disebabkan :

(1) Terdapat beberapa penyakit yang hanya membutuhkan hari perawatan rata-rata dibawah 6 hari.

(2) Jumlah sarana prasaranan dan SDM belum sebanding dengan frekuensi pelayanan resep obat jadi.

\section{b) Mutu Klinik}

Capaian indikator ini secara keseluruhan belum optimal dengan skor 10,50 dari bobot 12,00 . Indikator yang belum maksimal adalah angka kematian/kebutaan $\geq 48 \mathrm{jam}$.

Kurang maksimalnya capaian indikator tersebut disebabkan :

(1) Kebanyakan pasien rujukan dan kondisinya saat dirujuk ke rumah sakit sudah jelek, sehingga angka kematian masih terlalu tinggi.

(2) Tempat timur ICU masih belum tercukupi.
(3) Ruang Observasi Intentif (ROI) belum difungsikan.

\section{c) Kepedulian Kepada Masyarakat}

Capaian indikator ini secara keseluruhan belum optimal dengan skor 3,50 dari bobot 4,00

Indikator yang belum maksimal adalah penyuluhan kesehatan.

Kurang maksimalnya capaian indikator tersebut disebabkan beberapa elemen penilaian akreditasi terkait penyuluhan kesehatan yaitu Pendidikan Pasien dan Keluarga $\quad(\mathrm{PPK}) \quad$ 1-6 belum mendapatkan nilai maksimal, sehingga berdampak pada capaian indikator penyuluhan kesehatan belum optimal.

\section{d) Kepuasan Pelanggan}

Capaian indikator ini secara keseluruhan belum optimal dengan skor 1,91 dari bobot 2,00. Indikator yang belum maksimal adalah kepuasan pelanggan. Kurang maksimalnya capaian indikator tersebut disebabkan kepuasan masyrakat atas beberapa unsur penilaian Indeks Kepuasan Masyarakat (IKM) masih mendapatkan nilai rendah, diantaranya prosedur pelayanan dan kepastian biaya pelayanan. 


\section{e) Kepedulian}

Terhadap

\section{Lingkungan}

Capaian indikator ini secara keseluruhan belum optimal dengan skor 2,50 dari bobot 3,00. Indikator yang belum maksimal adalah kepedulian terhadap lingkungan. Kurang maksimalnya capaian indikator tersebut disebabkan beberapa elemen penilaian akreditasi terkait kepedulian terhadap lingkungan yaitu Pencegahan dan Pengendalian Infeksi (PPI) 7,2 dan 7,3, Manajemen Fasilitas dan Kesehatan (MFK) 2, 5, 10 dan 11,1 belum mendapatkan nilai maksimal.

Terhadap kondisi - kondisi diatas kepada Direktur RSUD Dr. Soegiri Lamongan telah kami sarankan agar melakukan langkah-langkah strategis untuk meningkatkan kinerja aspek pelayanan melalui :

(1) Menginstruksikan kepada setiap PPA (Petugas Pemberi Asuhan) agar menuliskan catanan kedalam berkas rekam medik segera setelah selesai memberikan pelayanan kepada pasien.

(2) Menambah tempat tidur ICU (Intensife Care Unit).

(3) Memfungsikan Ruang Observasi Intersife (ROI).
(4) Meningkatkan kualitas penyuluhan kesehatan (PPK 1-6) untuk mendapatkan nilai maksimal.

(5) Meningkatkan kualitas kepedulian terhadap lingkungan (PPI 7.2, PPI 7.3, MFK 2, MFK 5, MFK 10 dan MFK 11.1) untuk mendapatkan nilai maksimal.

(6) Menindaklanjuti hasil capaian Indeks Kepuasan Masyarakat melalui perbaikan unsur prosedur pelayanan dan kepastian biaya pelayanan.

(7) Memenuhi standar input minimal untuk pelayanan farmasi.

\section{Capaian Standar Pelayanan Minimal (SPM)}

RSUD Dr. Soegiri belum memiliki Standar Pelayanan Minimal yang ditetapkan dengan Peraturan Bupati. Namun, pada pelaksanaannya RSUD Dr. Soegiri Lamongan berpedoman pada Keputusan Menteri Kesehatan Nomor 129/Menkes/SK/II/2008 tanggal 8 Februari 2008 tentang SPM Rumah Sakit dalam menghitung capaian Standar Pelayanan Minimal.

Dari 12 jenis pelayanan $(90$ indikator) terdapat 11 pelayanan (19 indikator) yang belum sepenuhnya memenuhi standar yang ada. 


\begin{tabular}{|c|c|c|c|c|}
\hline No. & $\begin{array}{c}\text { Jenis } \\
\text { Layanan }\end{array}$ & $\begin{array}{c}\text { Jumlah } \\
\text { Indikator }\end{array}$ & $\begin{array}{c}\text { Ter } \\
\text { capai }\end{array}$ & $\begin{array}{c}\% \\
\text { Capaian }\end{array}$ \\
\hline 1 & $\begin{array}{l}\text { Gawat } \\
\text { Darurat }\end{array}$ & 8 & 6 & 75,00 \\
\hline 2 & Rawat Jalan & 6 & 6 & 100,00 \\
\hline 3 & Rawat Inap & 11 & 9 & 81,82 \\
\hline 4 & $\begin{array}{l}\text { Bedah } \\
\text { Sentral }\end{array}$ & 7 & 7 & 100,00 \\
\hline 5 & $\begin{array}{l}\text { Persalinan, } \\
\text { Perinatologi } \\
\text { (kecuali } \\
\text { rumah sakit } \\
\text { khusus di luar } \\
\text { rumah sakit } \\
\text { ibu dan anak) } \\
\text { dan KB. }\end{array}$ & 8 & 5 & 62,50 \\
\hline 6 & Intensif & 2 & 1 & 50,00 \\
\hline 7 & Radiologi & 4 & 4 & 100,00 \\
\hline 8 & $\begin{array}{l}\text { Laboratorium } \\
\text { Patologi } \\
\text { Klinik }\end{array}$ & 4 & 3 & 75,00 \\
\hline 9 & $\begin{array}{l}\text { Rehabilitasi } \\
\text { Medik }\end{array}$ & 3 & 3 & 100,00 \\
\hline 10 & Farmasi & 4 & 3 & 75,00 \\
\hline 11 & Gizi & 3 & 3 & 100,00 \\
\hline 12 & $\begin{array}{l}\text { Transfusi } \\
\text { Darah }\end{array}$ & 2 & 1 & 50,00 \\
\hline 13 & $\begin{array}{l}\text { Pelayanan } \\
\text { Gakin }\end{array}$ & 1 & 1 & 100,00 \\
\hline 14 & $\begin{array}{l}\text { Rekam } \\
\text { Medik }\end{array}$ & 4 & 2 & 50,00 \\
\hline 15 & $\begin{array}{l}\text { Pengelolaan } \\
\text { Limbah }\end{array}$ & 2 & 1 & 50,00 \\
\hline 16 & $\begin{array}{l}\text { Administrasi } \\
\text { dan } \\
\text { Manajemen }\end{array}$ & 9 & 6 & 66,67 \\
\hline 17 & $\begin{array}{l}\text { Ambulance / } \\
\text { Kereta } \\
\text { Jenazah }\end{array}$ & 3 & 3 & 100,00 \\
\hline 18 & $\begin{array}{l}\text { Pemulasaran } \\
\text { Jenazah }\end{array}$ & 1 & 1 & 100,00 \\
\hline 19 & $\begin{array}{l}\text { Pelayanan } \\
\text { Pemeliharaan } \\
\text { Sarana } \\
\text { Rumah Sakit }\end{array}$ & 3 & 1 & 33,33 \\
\hline 20 & $\begin{array}{l}\text { Pelayanan } \\
\text { Laundry }\end{array}$ & 2 & 2 & 100,00 \\
\hline
\end{tabular}

\begin{tabular}{|c|l|c|c|c|}
\hline No. & \multicolumn{1}{|c|}{$\begin{array}{c}\text { Jenis } \\
\text { Layanan }\end{array}$} & $\begin{array}{c}\text { Jumlah } \\
\text { Indikator }\end{array}$ & $\begin{array}{c}\text { Ter } \\
\text { capai }\end{array}$ & $\begin{array}{c}\text { \% } \\
\text { Capaian }\end{array}$ \\
\hline 21 & $\begin{array}{l}\text { Pencegahan } \\
\text { dan } \\
\text { Pengendalian } \\
\text { Infeksi }\end{array}$ & 3 & 3 & 100,00 \\
\hline & & & & \\
\hline & Jumlah & $\mathbf{9 0}$ & $\mathbf{7 1}$ & $\mathbf{7 8 , 8 9}$ \\
\hline
\end{tabular}

Terhadap kondisi-kondisi di atas kepada Direktur RSUD Dr. Soegiri Lamongan kami sarankan agar melakukan langkah-langkah strategis untuk meningkatkan capaian standar pelayanan minimal melalui :

(1) Meningkatkan pelatihan PPGD, BCTLS bagi perawat

(2) SOP visite dokter disesuaikan dengan

Kepmenkes 129/Menkes/SK/II/2008.

(3) Memfungsikan Ruang Observasi Intentif (ROI)

(4) Meningkatkan koordinasi dengan unit layanan pra rumah sakit.

(5) Meningkatkan skill tenaga perawat mahir dalam pelayanan intensif.

(6) Menambah dokter Spesialis Patologi Klinik.

(7) Menginstruksikan kepada dokter untuk menulis resep sesuai dengan formularium.

(8) Menginstruksikan agar setiap PPA (Petugas Pemberi Asuhan) menuliskan catatan kedalam berkas rekam medik segera setelah 
selesai memberikan pelayanan kepada pasien.

(9) Meningkatkan capaian parameter dalam indikator standar minimal air limbah yang tidak memenuhi baku mutu (ambang batas yang ditolerir) yaitu parameter $\mathrm{NH}-3$

(10) Meningkatkan anggaran pelatihan bagi karyawan rumah sakit.

(11) Menambah tenaga instalasi pemeliharaan sarana.

\section{Penyusunan dan Pelaksanaan} Rencana Bisnis dan Anggaran (RBA)

\section{a) Penyusunan RBA}

RSUD Dr. Soegiri Lamongan telah menyusun RBA tahun 2017, namun belum definitif, belum ditandatangani oleh Direktur RSUD Dr. Soegiri Lamongan selaku Pimpinan BLUD, belum diketahui oleh Dewan Pengawas dan telah disampaikan kepada Pejabat Pengelola Keuangan Daerah (PPKD).

b) Pelaksanaan RBA

Realisasi pendapatan dan belanja RSUD Dr. Soegiri Lamongan tahun 2017 dibandingkan dengan anggranan yang tercantum dalam RBA tidak bisa dicantumkan karena
RBA RSUD Dr., Soegiri Lamongan belum definitif.

\section{Hal-Hal Lain Yang Perlu Diperhatikan}

Uraian hal-hal lain yang perlu mendapat perhatian dalam rangka meningkatkan kinerja, tata kelola maupun pengendalian RSD BLUD.

1) Rencana Bisnis Anggaran (RBA) Difinitif Belum Dibuat

Rumah Sakit Umum Daerah (RSUD) Dr. Soegiri Lamongan sudah membuat Rencana Bisnis Anggaran (RBA) namun belum definitif, Belum ditandatangani Direktur Rumah Sakit dan belum diketahui Dewan Pengawas.

Sesuai dengan Peraturan Menteri Dalam Negeri Nomor 61 Tahun 2017 tentang Pedomanan Teknis Pengelolaan Keuangan Badan Layanan Umum Daerah dinyatakan bahwa setelah Rancangan Peraturan Daerah tentang APBD ditetapkan menjadi Peraturan Daerah, pemimpin BLUD melakukan penyesuaian terhadap RBA untuk ditetapkan menjadi RBA definitif.

Terhadap masalah tersebut kami sarankan kepada Direktur RSUD Dr. Soegiri Lamongan agar 
menyesuaikan RBA yang diajukan ke PPKD menjadi RBA definitif.

2) Standar Pelayanan Minimal Belum Ditetapkan Dengan Peraturan Bupati Lamongan

RSUD Dr. Soegiri Lamongan belum memiliki standar pelayanan minimal yang ditetapkan oleh Bupati Lamongan sebagai acuan bagi rumah sakit dalam melaksanakan standar pelayanan minimalnya.

Sesuai dengan Peraturan Menteri Dalam Negeri Nomor 61 Tahun 2017 tentang Pedomanan Teknis Pengelolaan Keuangan Badan Layanan Umum Daerah pasal 55 dinyatakan bahwa untuk menjamin ketersediaan, keterjangkauan dan kualitas pelayanan umum yang diberikan oleh BLUD dengan Peraturan Kepala Daerah.

Terhadap masalah tersebut kami sarankan kepada Direktur RSUD Dr. Soegiri Lamongan agar mengusulkan kepada Bupati Lamongan untuk menetapkan Standar Pelayanan Minimal dengan Peraturan Bupati.
3) Susunan Dewan Pengawas RSUD Belum Memadai

Dewan Pengawas BLUD RSUD Dr. Soegiri Lamongan terakhir dibentuk dengan Keputusan Bupati Lamongan Nomor 188/154/Kep/413.013/2017 tanggal 20 Juni 2017, tentang dewan pengawas satuan kerja perangkat daerah pola pengelolaan keuangan badan layanan umum daerah RSUD Dr. Soegiri Kabupaten Lamongan Tahun 2014 - 2019.

Di dalam Keputusan Bupati tersebut salah satu anggota dewan pengawas adalah Kepala Dinas Kesehatan Kabupaten Lamongan.

Pada tanggal 13 Juli 2017 dengan Surat Perintah Pelaksana Tugas Bupati Lamongan Nomor 800/141/413.205/2017, Kepala Dinas Kesehatan Lamongan diangkat sebagai Pelaksana Tugas Direktur RSUD Dr. Soegiri Lamongan. Dengan demikian Pelaksana Tugas Direktur RSUD Dr. Soegiri Lamongan merangkap sebagai anggota Dewan Pengawas RSUD Dr. Soegiri Lamongan.

Terhadap masalah tersebut kami sarankan kepada Ketua Dewan Pengawas RSUD Dr. Soegiri 
Lamongan agar menginformasikan perangkapan jabatan tersebut kepada Bupati Lamongan.

4) Dewan Pengawas Belum Melaksanakan Kewajiban Sesuai Ketentuan

Dari hasil evaluasi terhadap kinerja RSUD Dr. Soegiri Lamongan ditemukan bahwa masih terdapat kewajibankewajiban Dewan Pengawas RSUD Dr. Soegiri Lamongan yang belum dilaksanakan antara lain :

- Memberikan pendapat dan saran kepada Bupati mengenai Rencana Bisnis Anggaran (RBA) yang diusulkan oleh pejabat pengelola.

- Melakukan evaluasi dan penilaian kinerja baik keuangan maupun non keuangan.

Sesuai dengan Peraturan Bupati Lamongan Nomor 41 Tahun 2016 tentang Pola Tata Kelola Rumah Sakit Umum Daerah Dr. Soegiri Kabupaten Lamongan pasal 19 antara lain disebutkan bahwa Dewan Pengawas berkewajiban:

- Memberi pendapat dan saran kepada Bupati mengenai Rencana Bisnis Anggaran (RBA) yang diusulkan oleh pejabat pengelola.
- Melakukan evaluasi dan penilaian kinerja baik keuangan maupun non keuangan.

Terhadap masalah tersebut kami sarankan kepada Dewan Pengawas RSUD Dr. Soegiri Lamongan agar melaksanakan kewajiban sesuai dengan Pedoman Tata Kelola Rumah Sakit dan Ketentuan lainnya yang terkait.

5) Pelayanan Pengelolaan Limbah Belum Maksimal

Hasil cek fisik pada Unit Layanan Instalasi Pengelolaan Limbah (IPL), tanggal 25 Juli 2018 diperoleh informasi sebagai berikut :

- Bangunan Instalasi Pengelolah Limbah ternyata lokasinya sangat berdekatan dengan Ruang Rawat Inap Melati, tingkat kebisingan suara mesin IPL sangat mengganggu keberadaan pasien, sehingga kesehatan, keselamatan dan kenyamanan pasien juga terganggu.

- Unit Kerja IPL belum didukung dengan SDM yang memiliki spesifikasi kelistrikan, padahal secara operasional tenaga kerja tersebut diperlukan untuk mendukung kinerja layanan 
internal yang bertugas mengoperasionalkan; IPAL, pompa-pompa, tandon air dan mesin incenerator.

- Kapasitas tandon air untuk memenuhi kebutuhan pelayanan masih perlu dievaluasi karena masih dibawah standar.

- Laporan keluhan pelanggan dalam hal ini keluhan dari Unit Kerja lain sebagai pengguna jasa IPL belum terdokumentasi secara baik.

- Saluran sanitasi pematus disekitar Ruang Rawat Inap Melati masih terbuka, sehingga mengganggu kenyamanan dan keselamatan pasien.

\section{KESIMPULAN DAN SARAN}

Hasil evaluasi terhadap capaian kinerja Rumah Sakit Umum Daerah Dr. Soegiri Kabupaten Lamongan tahun 2017, dapat disimpulkan sebagai berikut :

\section{Evaluasi Kinerja RSUD}

Evaluasi kinerja atas RSUD Dr. Soegiri merupakan evaluasi kinerja yang pertama kali dengan uraian ringkas sebagai berikut :

a. Aspek Keuangan

1) Laporan Keuangan
RSUD Dr. Soegiri telah menyusun laporan keuangan tahun 2017 sesuai standar akuntansi keuangan (SAK). Laporan keuangan RSUD Dr. Soegiri tahun 2017 telah diaudit oleh auditor independen (Kantor Akuntan Publik Made Sudarma-Thomas-Dewi) dengan opini wajar tanpa pengecualian sesuai laporan nomor AU085/MTD/SBY/III/2018 tanggal 26 maret 2018.

2) Kinerja Aspek Keuangan

Capaian kinerja keuangan tahun 2017 belum optimal dengan skor 18,03 atau $60,10 \%$ dari bobot 30 dengan rincian sebagai berikut:

a) Rasio Keuangan

Capaian kinerja rasio keuangan belum optimal dengan skor 10,85 atau $57,11 \%$ dari bobot 19

b) Kepatuhan Pengelolaan Keuangan RSUD

Capaian kinerja kepatuhan pengelolaan keuangan RSUD belum optimal dengan skor 7,18 atau 65,27\% dari bobot 11 .

b. Aspek Pelayanan

Capaian kinerja pelayanan tahun 2017 belum optimal dengan skor 59,41 atau 84,87 dari bobot 70 dengan rincian sebagai berikut:

1) Kualitas Layanan 
Capaian kinerja kualitas layanan belum optimal dengan skor 27,50 atau 78,57 dari bobot 35 .

2) Mutu dan Manfaat Kepada Masyarakat

Capaian kinerja mutu dan manfaat kepada masyarakat belum optimal dengan skor 31.91 atau 91,17 dari bobot 35.

\section{Standar Pelayanan Minimal (SPM)}

RSUD Dr. Soegiri belum memiliki Standar Pelayanan Minimal (SPM) yang ditetapkan dengan Peraturan Bupati Lamongan.

SPM yang disusun belum sepenuhnya mengacu kepada keputusan Menteri Kesehatan Nomor 129/MenKes/SK/II/2008 tanggal 8 Februari 2008 tentang SPM Rumah Sakit.

RSUD Dr. Soegiri telah melakukan penilaian atas capaian Standar Pelayanan Minimal (SPM) dengan hasil, dari 21 pelayanan, sebanyak 11 pelayanan belum mencapai SPM yang ditetapkan, yaitu:
a. Gawat Darurat
b. Rawat Inap
c. Persalinan dan Perinatologi
d. Intensif
e. Laboraturium Patologi Klinik

f.Farmasi

g. Tranfusi Darah

h. Rekam Medik

i.Pengelolaan Limbah

j.Administrasi dan Manajemen

k. Pelayanan Pemeliharaan Sarana Rumah Sakit

\section{Penyusunan dan Pelaksanaan} Rencana Bisnis dan Anggaran (RBA)

RSUD Dr. Soegiri belum menyusun RBA definitif tahun 2017 dan belum diserahkan kepada PPKD. RBA yang disusun belum diketahui oleh Dewan Pengawas.

RBA RSUD Dr. Soegiri belum sepenuhnya disusun dengan mengacu pada Rencana Strategis Bisnis (RSB)

Realisasi pendapatan dan biaya operasional tahun 2017 tidak dapat dibandingkan anggarannya karena RBA definitif belum dibuat.

\section{Hal-hal Lain Yang Perlu Diperhatikan}

1) Rencana Bisnis Anggaran (RBA) Difinitif belum dibuat

Rumah Sakit Umum Daerah (RSUD) Dr. Soegiri Lamongan sudah membuat Rencana Bisnis Anggaran (RBA) namun belum definitif, belum ditandatangani Direktur Rumah Sakit dan belum diketahui Dewan Pengawas. 
2) Standar Pelayanan Minimal belum ditetapkan dengan Peraturan Bupati Lamongan RSUD Dr. Soegiri Lamongan belum memiliki Standar Pelayanan Minimal yang ditetapkan oleh Bupati Lamongan sebagai acuan bagi Rumah Sakit dalam melaksanakan standar pelayanan minimalnya.

3) Susunan Dewan Pengawas RSUD Belum Memadai

Pelaksana tugas Direktur RSUD Dr. Soegiri Lamongan merangkap sebagai anggota Dewan Pengawas RSUD Dr. Soegiri Lamongan.

\section{4) Dewan Pengawas Belum}

Melaksanakan Kewajiban

\section{Sesuai Ketentuan}

Dari hasil evaluasi terhadap kinerja RSUD Dr. Soegiri Lamongan ditemukan bahwa masih terdapat kewajiban-kewajiban Dewan Pengawas RSUD Dr. Soegiri Lamongan yang belum dilaksanakan antara lain:

- Memberikan pendapat dan saran kepada Bupati Lamongan mengenai Rencana Bisnis Anggaran (RBA) yang diusulkan oleh pejabat pengelola.
- Melakukan evaluasi dan penilaian kinerja baik keuangan maupun non keuangan.

\section{5) Pelayanan Pengelolaan}

\section{Limbah Belum Maksimal}

Hasil cek fisik pada Unit Pelayanan Instalasi Pengelolaan Limbah (IPL) tanggal 25 Juli 2018 diperoleh informasi sebagai berikut:

- Bangunan Instalasi Pengolah Limbah (IPL) ternyata lokasinya sangat berdekatan dengan Ruang Rawat Inap Melati

- Unit kerja IPL belum didukung dengan SDM yang memiliki spesifikasi kelistrikan

- Kapasitas tandon air untuk memenuhi kebutuhan pelayanan masih perlu dievaluasi.

- Laporan keluhan pelanggan dalam hal ini keluhan dari unit kerja lain sebagai pengguna jasa IPL belum terdokumentasi dengan baik.

- Saluran sanitasi pematus disekitar Ruang Rawat Inap Melati masih terbuka.

\section{Saran}

Untuk meningkatkan kinerja dan kualitas layanan RSUD Dr. Soegiri kami sarankan kepada Direktur RSUD Dr. 
Soegiri agar melakukan langkah-langkah strategis untuk meningkatkan kinerja rumah sakit

\section{DAFTAR PUSTAKA}

Patton, Metode Penelitian Kuantitatif dan Kualitatif ( $7^{\text {th }}$ ed). Bandung. 2009.

Subanegara, Modul Pelatihan Standar Pelayanan Minimal, 2006.

Direktorat Jenderal Perbendaharaan, Modul Pengelolaan Keuangan Badan Layanan Umum.

Permedagri No. 61 / 2007, Pola Pengelolaan Keuangan Badan Layanan Umum Daerah, Jakarta, 2007.

Undang - Undang No. 44 / 2009, Rumah Sakit, Jakarta, 2009.

Permendagri No. 79 / 2018, Badan Layanan Umum Daerah, Jakarta, 2018. 